University of Konstanz

Department of Economics

\title{
The Evolution of Sharing Rules in Rent Seeking Contests: Incentives Crowd Out Cooperation
}

Heinrich Ursprung

Working Paper Series

2011-02 
THE EVOLUTION OF SHARING RULES IN RENT SEEKING CONTESTS: INCENTIVES CROWD OUT COOPERATION

21 February 2011

\begin{abstract}
Modern societies are characterized by competing organizations that rely predominantly on incentive schemes to align the behavior of their members with the organizations' objectives. This study contributes to explaining why in so many cases incentive schemes have gradually crowded out cooperation as an organization device. Our explanation does not draw on free-riding, the obvious Achilles' heel of cooperation, but relies completely on fundamental group contest mechanisms. By investigating a canonical rent seeking model and adopting an evolutionary perspective, the analysis identifies shortcomings in previous results, sets the record straight, and explains why the process of incentivizing organizations is protracted.
\end{abstract}

JEL Classification: D72, D74, M52

Keywords: group contests, rent-seeking, sharing rules, cooperation, incentives, evolution 


\section{THE EVOLUTION OF SHARING RULES IN RENT SEEKING CONTESTS: INCENTIVES CROWD OUT COOPERATION}

\section{Introduction}

Humans are inherently competitive. "Homo rivalis" competes for resources, mates, sports trophies, and even artistic and professional recognition. How contestants act out their competitive instincts depends on the prevailing cultural environment (cf. Chen and Tang 2009). Humans are, however, also social animals. A key canonical form of human interaction is therefore the group contest. Competition between groups takes place, for example, when, in an international river basin, riparian tribes dispute property rights to water (cf. Ansink and Weikard 2009). Competition between groups does of course not exclude competition within these groups; intra-group competition takes, for example, the form of advancement contests in private enterprises (the classical paper is Lazear and Rosen 1981) and public bureaucracies (cf. Kahana and Liu 2010). This paper analyzes inter-group contests in the presence of intragroup competition.

The rules that govern intra-group contests depend on the organization of the group. In a world in which groups do not exhibit even rudiments of organization, the group members -- even though they share common interests -- behave in a non-cooperative manner. This is Hobbes's war of all against all. Overcoming the Hobbesian jungle fortunately does not necessarily require a Leviathan. ${ }^{1}$ Cooperation among strangers can also emerge from a general willingness to punish non-cooperative behavior. Such decentralized punishment does not presuppose high moral standards on the part of the punisher; it is present even in rather unpleasant societies of thugs, ruffians, and thieves who actually like to cheat (cf. Heller and Sieberg 2010). In more tightly organized societies, punishment may be centralised, whereas the flow of information on deviant behavior may still rely on decentralized whistle blowing (cf. Arce 2010).

Cooperative behavior is, however, by no means the predominant form of intra-group interaction. Often, especially if the group's objective requires the commitment of resources, more sophisticated instruments of group organization are employed. In order to elicit optimal effort on the part of all group members, the contested group-specific excludable good can, for example, be shared among the members according to their respective effort. This kind of incentive scheme evidently makes do with less solidarity among group members and with less

\footnotetext{
${ }^{1}$ Hillman (2009) elaborates on how Hobbes backed his view of the role of the king (Leviathan) in the face of the misgivings put forward by the prophet Samuel.
} 
monitoring effort applied by the group's formateurs. In any event, incentives schemes arguable are the most important instrument of eliciting effort in modern organizations.

I analyze how a group's internal organization (which may differ from the opponent group's mode of organization) impacts on the group's external contest success. The insights gained from the analysis contribute to explaining the emergence of the ubiquitous use of incentive schemes in modern organizations. Our explanation has two novel aspects. First, it does not draw on the phenomenon of free-riding in large groups; it rather relies on mechanisms inherent in group contests that pit groups with different organizational schemes against one other. And second, it is couched in an evolutionary context that explains why it can take a long time for incentive schemes to crowd out cooperation.

This study relates to a substantial literature on group contests. It is by now, for example, well understood how rent seeking for group-specific public goods gives rise to free-riding. Ursprung (1990) investigates the case of identical group members and congestible public goods and arrives at the result that small groups outperform large groups - an insight which is reminiscent of Olson (1965). Baik (2008) assumes asymmetric valuations of the prize across group members; he shows that when players are budget-constrained, low-valuation members free-ride on high-valuation players. Epstein and Mealem (2009) investigate the extent to which contest success can be increased by orchestrating group membership. Intra-group sharing-rules that provide incentives to contribute to group effort were introduced by Nitzan (1991). Cheikbossian (2008) compares cooperative behavior with non-cooperative behavior of the group members. Baik and Shogren (1995) explain the formation of groups and Hausken (2000) shows how cooperation among group members may emerge in inter-group contests. Experimental work indicates that intergroup competition can promote efficient behavior of group members: Riechmann and Weimann (2008), for example, focus on coordination problems within groups and Reuben and Tyran (2010) test whether intra-group cooperation can be promoted by rank-order competition between groups in which all groups can be ranked first. Konrad (2009: chapter 6) provides an encompassing state of the art survey of this literature.

I investigate contests in which competing groups apply different intra-group organization schemes and sharing rules. In line with many contributions to the rent-seeking literature, the simplest set-up is employed, namely a two-group Tullock (1980) lottery contest with linear cost functions and symmetric valuation of the prize. I show in section 2 that intra-group cooperation in all respects dominates organization schemes that completely rely on 
spontaneous individual contributions (non-cooperative behavior). Moreover, groups using incentive schemes do better than cooperating groups as far as contest success is concerned, but fare worse with respect to expected individual utility. In section 3 I show that in a population of groups in which cooperation is used to organize the within-group interaction, incentive schemes will nevertheless catch on, albeit in a protracted evolutionary bootstrapping process. I arrive at the conclusion that the forces inherent in group contests see to it that pure incentive schemes completely crowd out schemes relying on cooperation and incomplete incentivising.

My analysis is closely related the literature that investigates the group sharing rule proposed by Shmuel Nitzan (1991) in this journal 20 year ago. Sanghack Lee (1995) endogenizes the choice of Nitzan's sharing rule but his analysis has problems. In section 3 I employ an evolutionary narrative to formally reinvestigate Lee's story line and show that even though the sub-game perfect Nash equilibrium identified by Lee is correct (as has also be confirmed in a more general context by Ueda, 2002), establishing the equilibrium sharing rule may not be as straightforward as Lee's analysis appears to convey. I rather show that the likely evolutionary process that eventually gives rise to the equilibrium sharing rule is protracted and takes time to run its course. More recent contributions deal with group contests in which the sharing rule of the opponent group is not observed (Baik and S. Lee 2007; Nitzan and Ueda 2010; Baik and D. Lee forthcoming).

\section{Pure types of group organization}

Consider two groups contesting a prize. Group $k$ has $n_{k}$ identical risk-neutral members $(k=1,2)$. The contest effort of member $i$ of group $k$ is denoted by $\mathrm{x}_{\mathrm{ik}}$. Total contest outlays of group $k$ then amount to $X_{k}=\sum_{i=1}^{n_{k}} x_{i k}$. Furthermore, assume the contest technology to be of the Tullock (lottery) variety with linear cost of effort and that everybody values the prize at $\mathrm{V}$. If the groups are not organized, i.e., if the members of group $k$ do not cooperate among each other, and the prize is shared equally among the group members of the successful group, the expected utility $E U_{i 1}^{N}$ of member $i$ of group 1 ( $N$ signifies non-cooperation) amounts to

$$
E U_{i 1}^{N}=\frac{X_{1}}{X_{1}+X_{2}} \frac{V}{n_{1}}-x_{i 1} .
$$

The respective expression for a representative member $j$ of group 2 is symmetric. Instead of 
interpreting the lottery outcome $p_{1}=X_{1} /\left(X_{1}+X_{2}\right)$ to represent the probability of winning, one could just as well interpret this expression to represent the share of the rent assigned by the contest to group 1. This isomorphism follows from assuming risk neutrality. The assumed contest technology is nevertheless rather special. Alternative specifications could, for example, assume a generalized logit contest success function (as in Epstein and Mealem 2009), a completely discriminating contest as pioneered in the rent-seeking literature by Hillman and Samet (1987) and Hillman and Riley (1989) and applied to group contests by Konrad (2004), a dynamic framework that takes into account that many prizes endure over time and may have to be re-contested (as in Aidt and Hillman 2008), or even asymmetric information (as in Ryvkin 2010).

If the group members cooperate as, for example, in a soccer team, the expected utility $E U_{i 1}$ has the following appearance:

$$
E U_{i 1}=\frac{X_{1}}{X_{1}+X_{2}} \frac{V}{n_{1}}-\frac{X_{1}}{n_{1}}
$$

Cooperation is thus meant to imply that the gain and the pain (i.e., the prize and the effort) are shared equally among the group members. Whether all group members will truly exert the same effort in cooperation is of course always uncertain. Because of this moral hazard problem, enforcing perfect cooperation is notoriously difficult. Assuming that only a fraction $q \in[0,1]$ of the members cooperate, the expected utility of the co-operators is reduced because now the contributions are shared by only $q n_{1}$ members $(C$ signifies qualified cooperation):

$$
E U_{i 1}^{C}=\frac{X_{1}}{X_{1}+X_{2}} \frac{V}{n_{1}}-\frac{X_{1}}{q n_{1}} .
$$

Notice that the parameter $\mathrm{q}$ is assumed to be the same for both groups. It can also be interpreted to measure cost-efficiency in sustaining cooperation, costless enforcement of cooperation being portrayed by $\mathrm{q}=1$.

The third archetype of group organization uses incentive schemes to elicit private effort $x_{i k}$. The standard example for such a contest is competition among business firms whose employees are remunerated according to performance. Following the seminal study of sharing rules in group contests by Nitzan (1991), one can portray the intricate intra-group and intergroup interactions of a group that uses this incentive scheme as follows ( $I$ signifies incentive scheme): 


$$
E U_{i 1}^{I}=\frac{X_{1}}{X_{1}+X_{2}} \frac{x_{i 1}}{X_{1}} V-x_{i 1}=\frac{x_{i 1}}{X_{1}+X_{2}} V-x_{i 1}
$$

This representation implies that each member obtains the share of the prize that corresponds to the share of his or her contribution to the group's total effort. ${ }^{2}$

Allowing these three possible types of group organization, nine different kinds of contests need to be analyzed in a two-group contest model. To do so, the expected utility functions in the equations $(1 N),(1 C)$ and $(1 I)$ are differentiated with respect to individual effort $x_{i k}$. Applying the symmetry condition $\mathrm{x}_{\mathrm{ik}}=\mathrm{x}_{\mathrm{k}}$ (for all $i$ ) after differentiation yields the following three pairs of reaction functions $(k \neq \ell=1,2)$.

$$
\begin{aligned}
& \frac{X_{\ell}}{\left(X_{k}+X_{\ell}\right)^{2}} \frac{V}{n_{k}}-1=0 \\
& q \frac{X_{\ell}}{\left(X_{k}+X_{\ell}\right)^{2}} V-1=0 \\
& \frac{\left(n_{k}-1\right) x_{k}+X_{\ell}}{\left(X_{k}+X_{\ell}\right)^{2}} V-1=0
\end{aligned}
$$

Combining the reaction functions of the three types of group organization $(\mathrm{N}, \mathrm{C}, \mathrm{I})$ with each other yields the nine Nash equilibria summarized in Table $1 .^{3}$ Table 1 reports the probability $\mathrm{p}_{\mathrm{k}}$ of group $k(k=1,2)$ winning the contest, the expected utility $E U_{\mathrm{ik}}$ of a representative member of the two competing groups, and total rent dissipation $D=X_{1}+X_{2}$ which has played a major role in the literature on rent-seeking contests. ${ }^{4}$ Without loss of generality the valuation is set equal to unity $(\mathrm{V}=1)$.

Comparing in Table 1 the entries in the NN-cell with those in the $\mathrm{CN}$-cell (or the NC cell) shows that it is profitable to organize a group of agents who share a common interest. If group 1 manages to get organized but group 2 remains unorganized, the probability $p_{1}$ of group 1 succeeding in the group contest increases from $n_{2} /\left(n_{1}+n_{2}\right)$ to $n_{2} /\left(1+n_{2}\right)$. This increase in contest prowess is accompanied by an increase in the organized group members' expected utility: $E U_{i 1}^{C N}>E U_{i 1}^{N N}$ (we assume here and in the following that the fraction $q$ of co-operators

\footnotetext{
${ }^{2}$ An alternative way of modelling the distribution of the spoils within the winning group is to stage a second rent-seeking contest among the members of the successful group. The respective classical paper is Katz and Tokatlidu (1996).

${ }^{3}$ The few free riders in the groups banking on cooperation do not contribute anything. We assume that the stake of these defectors does not influence the group's choice of the mode of organization.

${ }^{4}$ A collection of 'classical' studies of rent-seeking contests is to be found in Congleton, Hillman and Konrad (2008). For a recent empirical study that measures rent dissipation in Europe, see Angelopoulos et al. (2009).
} 
is large, i.e., close to unity). Even though each member has to contribute more when cooperation is imposed, ${ }^{5}$ this additional private cost is more than compensated by the increased likelihood of obtaining the shared prize. Thus, if the cost of organizing a group is sufficiently low, i.e., if $\mathrm{q}$ is sufficiently large, one would expect the group to become organized. Notice that total rent dissipation D increases as a consequence of this maneuver. This loss or waste of resources is reflected in a reduction of expected utility for the members of the unorganized group 2 who will therefore also consider becoming organized. In this they will certainly succeed because this shift from cell $\mathrm{CN}$ to cell $\mathrm{CC}$ is associated with an increase in expected contest success $\mathrm{p}_{2}$ and expected utility $E U_{j 2}$. Rent dissipation D again increases, implying that the members of group 1 will do worse when their opponent is organized.

For sufficiently low costs of organization (q close to unity), cooperation thus becomes the preferred mode of within-group behavior. In terms of Table 1 this implies that escaping the Hobbesian jungle as portrayed by cell $\mathrm{NN}$ is simply a matter of evolutionary discovery. In other words, the society moves from NN to CC. The CC-regime is, however, not a Garden of Eden since cooperation is not universal but limited to the interaction between (most) members of the same group. Even though all groups eventually adopt the cooperative regime, the move from $\mathrm{NN}$ to $\mathrm{CC}$ thus does not increase the welfare of all; as a matter of fact, at least one group will lose and, if the group sizes are not too different, both of them will lose (the N-C game is then a prisoners' dilemma). This is so because rent dissipation increases from $V /\left(n_{1}+n_{2}\right)$, i.e., the average stake of the individual contestant, to $q V / 2$, while the prize remains constant.

The model thus suggests that when competing organizations can choose whether to have intra-group cooperation or not, the likely outcome is for both to adopt the cooperative regime. The following question then arises: is intra-group cooperation an evolutionary equilibrium or can at least one of the groups do better by adopting the pure incentive scheme described by equation (1I)? To answer this question we need to distinguish between two cases: costless or perfect cooperation $(\mathrm{q}=1)$ and the realistic case in which inducing cooperation is costly or less than perfect $\left(\mathrm{q}<1\right.$ or rather $\left.q \leq\left(n_{k}-1\right) / n_{k}, \mathrm{k}=1,2\right){ }^{6}$ Comparing the CC-cell in Table 1 with the IC (or CI) cell reveals that adopting the incentive scheme $I$ increases the innovating group's probability of winning the group contest. Thus, if the group formateur's objective were to maximize the probability of winning (maybe because the group members use this as a

${ }^{5} x_{1}^{C N}=\frac{n_{2}}{\left(1+n_{2}\right)^{2}}>x_{1}^{N N}=\frac{n_{2}}{\left(n_{1}+n_{2}\right)^{2}}$

${ }^{6}$ Notice that the seeming discontinuity in the values (for $\mathrm{q}=1$ and $\mathrm{q}<1$ ) of the variables reported in the CI and IC cells of Table 1 derives from the fact that $\mathrm{q}$ is not a continuous variable. 
measure of the formateur's performance) the formateur would indeed introduce the incentive scheme $I$. Introducing the incentive scheme $I$ does, on the other hand, reduce the expected utility of the innovating group: $E U_{1 i}^{C C}>E U_{1 i}^{I C}\left(E U_{2 j}^{C C}>E U_{2 j}^{C I}\right){ }^{7}$ This result rather suggests that incentives would not be introduced in a situation in which both groups bank on cooperation. In the next section it is, however, shown that the cooperative regime $\mathrm{CC}$ is not a steady state: using incentives to some limited extent against a group of co-operators proves to be advantageous.

\section{Bootstrapping incentive schemes}

Starting out from the CC regime, assume that group 1 is innovative and introduces the group sharing rule proposed by Nitzan (1991) and thoroughly re-investigated by Davis and Reilly (1999). This rule entails a convex combination of laissez faire (non-cooperation) and the pure incentive scheme $I$ analyzed in the previous section. To keep the story line as simple as possible, assume now that both groups have the same number of members: $n_{1}=n_{2}=n$. For $\mathrm{V}=1$, the expected utility $E U_{i 1}^{M}$ of member $i$ of group 1 in this case is

$$
E U_{i 1}^{M}=\frac{X_{1}}{X_{1}+X_{2}}\left(a_{1} \frac{1}{n}+\left(1-a_{1}\right) \frac{x_{i 1}}{X_{1}}\right)-x_{i 1},
$$

where $a \in[0,1]$ denotes the relative weight given to equal distribution of the prize as compared to effort-related distribution, and the superscript $M$ indicates that the group uses this mixed sharing rule. The non-cooperative group organization $N$ is therefore characterized by $a=1$ and the pure incentive scheme $I$ by $a=0$. The associated reaction function has the following appearance:

$$
\frac{X_{2}}{\left(X_{1}+X_{2}\right)^{2}} \frac{1}{n}+\left(1-a_{1}\right) \frac{n-1}{n} \frac{1}{X_{1}+X_{2}}-1=0 .
$$

To see whether switching to the mixed incentive scheme pays off, combine $(2 M)$ with $(2 C)$ to arrive at the Nash equilibrium in the asymmetric contest in which group 1 adopts the mixed incentive scheme $M$ and group 2 banks on cooperation. This exercise yields

\footnotetext{
${ }^{7}$ For $\mathrm{q}=1$ this statement presupposes $\mathrm{n}_{\mathrm{k}}>4$.
} 


$$
\begin{aligned}
& X_{2}=\varphi X_{1} \text {, where } \varphi=\max \left(\frac{q n-\left(1-a_{1}\right)(n-1)}{1+\left(1-a_{1}\right)(n-1)}, 0\right) \text { and } \\
& E U_{i 1}^{M C}=\left(\frac{1}{1+\varphi}-\frac{q}{(1+\varphi)^{2}}\right) \frac{1}{n} .
\end{aligned}
$$

If $a<\bar{a} \equiv \frac{(1-q) n-1}{n-1}, \varphi$ becomes zero, i.e., the co-operator group 2 will abstain from competing: $\mathrm{X}_{2}=0 .{ }^{8} \quad$ In this case $(2 M)$ yields $\mathrm{X}_{1}=\mathrm{q}$, and, according to (3), $E U_{i 1}^{M C}\left(a_{1}=\bar{a}\right)=(1-q) / n$. Thus, for sufficiently well working groups of co-operators $(\mathrm{q}>3 / 4)$, it does not pay to adopt the mixed incentive scheme with $a=\bar{a}$ since $E U_{i 1}^{M C}\left(a_{1}=\bar{a}\right)<E U_{i 1}^{C C}=\frac{1}{4 n}$.

This is, however, not the end of the story because making the opponent group surrender is not the best option here. Maximizing $E U_{i 1}^{M C}$ in (3) with respect to the weight $a$ yields the optimal weight to be applied by group 1: $a^{*}=\frac{q n-1}{2 q(n-1)}$. Substituting $a^{*}$ into the expected utility function $(1 M)$ results in $E U_{i 1}^{M C}\left(a_{1}=a^{*}\right)=\frac{1}{q} \frac{1}{4 n}>\frac{1}{4 n}=E U_{i 1}^{C C}$ for $\mathrm{q}<1$. Group 1 may therefore adopt the mixed incentive scheme with the weight $a^{*}$. Notice that even though assuming $\mathrm{q}<1$ is required at this stage to kick off the process, this assumption is innocuous since it is only used to destroy a knife-edge equilibrium, i.e., any value of $\mathrm{q}<1$ arbitrarily close to 1 is sufficient to produce the sought-after result which would also arise from a trembling hand type of argument. ${ }^{9}$

Introducing the mixed incentive scheme with the weight $\mathrm{a}^{*}$ thus increases the welfare of the members of the innovating group. It also increases the innovating group's probability of winning the inter-group contest: $p_{1}$ increases from $1 / 2$ to $1 / 2 q$. Incentivising individual contributions is advantageous because the mixed organization rule parameterized by the instrument variable $a$ serves as a commitment device. Reducing $a$, i.e., providing more

\footnotetext{
${ }^{8}$ Notice that $\bar{a}>0$ for $\mathrm{q}<(\mathrm{n}-1) / \mathrm{n}$, i.e., if at least two group members do not cooperate.

${ }^{9}$ Notice, that for small group sizes the largest $\mathrm{q}<1$ may be substantially smaller than 1 . Moreover, and more importantly, if the group sizes differ the assumption that $\mathrm{q}$ applies to both groups cannot be satisfied for small groups. Suppose, for example, that $\mathrm{n}_{1}=2$ and $\mathrm{n}_{2}=3$. The only values $\mathrm{q}$ can take for group 1 are 0.5 and 1 , and for group 2 they are $1 / 3,2 / 3$ and 1 - so q cannot be the same for both groups if it is below 1 . The analysis in section 2 does therefore, strictly speaking, apply only to large groups, and also there only as an approximation. The above restriction $\mathrm{n}_{1}=\mathrm{n}_{2}=\mathrm{n}$ thus cannot easily be abandoned.
} 
incentives, increases total contest outlays of group 1: $X_{1}=\varphi^{-1} X_{2}$ (see equation 3 above). By manipulating $a$, the first group is thus in a position to control $\mathrm{X}_{1}$. Group 2 can also control total contest outlays, i.e., $\mathrm{X}_{2}$, but group 1 , by establishing the organization scheme parameterized by $a$, has the advantage of being able to commit to a response to whatever group 2 decides to do. And this advantage translates into an increase in contest success.

How group 2 will behave after group 1 has introduced the mixed incentive scheme $a^{*}$ depends on its decision-making routine. Assume group 2 to be unimaginative and to follow a strategy of copying the opponent group's organization policy if that group happens to be more successful. Group 2 thus follows suit and adopts the mixed incentive scheme used by group 1 . Will, by doing so, group 2 be better off and therefore stick with this new organization scheme? To answer this question one needs to solve the first-order condition $(2 M)$ for $\mathrm{X}_{1}=\mathrm{X}_{2}=\mathrm{X}$ because we now have perfect symmetry between the two groups: $a_{1}=a_{2}=a^{*}$. Substituting the resulting $\mathrm{X}$ in the expected utility function $(1 M)$ yields

$$
E U_{i 1}^{M M}\left(a^{*}, a^{*}\right)=E U_{j 2}^{M M}\left(a^{*}, a^{*}\right)=\frac{1+2 a^{*}(n-1)}{4 n^{2}}>E U_{j 2}^{M C}\left(a=a^{*}\right)=\left(\frac{2 q-1}{2 q}\right)^{2} \frac{1}{n} .
$$

The imitator group 2 will therefore adopt and stick with the incentive scheme a* after the innovative group 1 has done so. This result establishes that a transition from the cooperative regime $\mathrm{CC}$ to a regime in which both groups adopt a mixed incentive scheme $\mathrm{M}$ is likely to eventually take place even if the two groups adhere to simple behavioral strategies of groping. The next step is to show that the situation in which both groups adopt the same mixed incentive scheme $\mathrm{M}$ with weights $a_{1}=a_{2}=a>0$ is not an equilibrium: each of the two groups has an incentive to unilaterally decrease the weight $a_{k}$ given to equal sharing, i.e., each group $k$ benefits from providing the organization scheme with some additional private incentives to contribute to the success of the group contest. To show that this is so, combine the reaction functions $(2 M)$ for $a_{1}<a_{2}$ to obtain

$$
X_{2}=\psi X_{1}, \text { where } \psi=\max \left(\frac{1-(n-1)\left(a_{2}-a_{1}\right)}{1+(n-1)\left(a_{2}-a_{1}\right)}, 0\right)
$$

If our innovative group 1 decreases the weight $\mathrm{a}_{1}$ on equal distribution too much, the members of the opposing group 2 will refrain from competing: $\mathrm{X}_{2}=0$. As can be seen from equation (5) this happens when $a_{1} \leq a_{2}-1 /(n-1)$. If $X_{2}=0$, the members of group 1 compete only among themselves. Maximizing expected utility then yields 


$$
E U_{i 1}^{M M}\left(a_{1}<a_{2}-1 /(n-1)\right)=\frac{1+a_{1}(n-1)}{n^{2}} .
$$

If, on the other hand, $a_{2}>a_{1}>a_{2}-1 /(n-1)$, the members of group 2 remain active: $\mathrm{X}_{2}>0$. Substituting $X_{2}=\psi X_{1}$ into the expected utility function (1M) yields

$$
E U_{i 1}^{M M}\left(a_{2}>a_{1}>a_{2}-1 /(n-1)\right)=\frac{1+2 a_{2}(n-1)+\left(a_{2}^{2}-a_{1}^{2}\right)(n-1)^{2}}{4 n^{2}} V .
$$

Decreasing $a_{1}$ from $a_{1}=a_{2}$ down to $a_{1}=a_{2}-1 /(n-1)$ thus increases the expected utility $E U_{i 1}^{M M}$ of group 1. Decreasing $a_{1}$ further will, according to equation (6), decrease expected utility. The optimal strategy for group 1 is therefore to set $a_{1}\left(a_{2}\right)=\max \left(a_{2}-1 /(n-1), 0\right)$. If group 1 implements this strategy, the utility of the members of group 2 will be zero, which is less than what they get if they copy their more successful opponent and also adopt the weight $\mathrm{a}_{1}$ (see equation 4): $E U_{j 2}^{M M}\left(a_{1}, a_{1}\right)=\left(1+2 a_{1}(n-1)\right) \frac{V}{4 n^{2}}>0$. Starting out from a situation in which both groups adopt the mixed organization scheme $\mathrm{M}$ with the weights $a_{1}=a_{2}=a$ one arrives at a situation in which both groups provide their organization with more incentives to contribute: $a_{1}=a_{2}=a-1 /(n-1)$. This competition to the bottom continues until a positive weight $a \leq 1 /(n-1)$ is reached. The last step is then to move to $\mathrm{a}=0$ which is equivalent to the pure incentive scheme $I$.

Figure 1 illustrates the game assuming, as I did so far, that the portrayed organizations are not far-sighted, present value maximizing agents. They are rather perceived as adhering to some kind of groping behavior that may, in particular, involve more or less systematic attempts to innovate and simple imitation, i.e., behavioral routines that do not imply contemplating strategic interaction with the attendant long run consequences. The starting point in Figure 1 is the situation in which both groups use the mixed incentive scheme with the weight $\mathrm{a}^{*} \cdot{ }^{10}$ As shown above, the best response of group 1 is given by the equation $a_{1}\left(a_{2}\right)=\max \left(a_{2}-1 /(n-1), 0\right)$. The evolution as narrated in the text, with group 1 always being the organizational innovator and group 2 the imitator, is portrayed by the solid arrows. The depicted adjustment path presupposes that group 1 always finds the best response to whatever group 2 is doing. If this is not the case, the "adjustment steps" may be of different

\footnotetext{
${ }^{10}$ A numerical example of the whole process starting from the absence of any organization (Hobbesian jungle) via the regime in which both groups bank on cooperation, the first adoption of a mixed incentive scheme to fully incentivized organizations is provided in the Appendix.
} 
size - most likely smaller because groping usually comes with a rather cautions behavior. Since for large groups the best response function $\mathrm{BR}_{1}$ of group 1 is very close to the $45^{\circ}$-line, the process of moving to a fully incentivised organization may take a long time. ${ }^{11}$ To be sure, if group 2 is assumed to be just as innovative as group 1, the process is sped up as indicated by the dashed arrows in Figure 1. Our main conclusion, however, remains valid: the trend of development towards fully incentivized group organization schemes is a protracted evolutionary (discovery) process.

\section{Figure 1: Reaction functions for non-identical sharing rules}

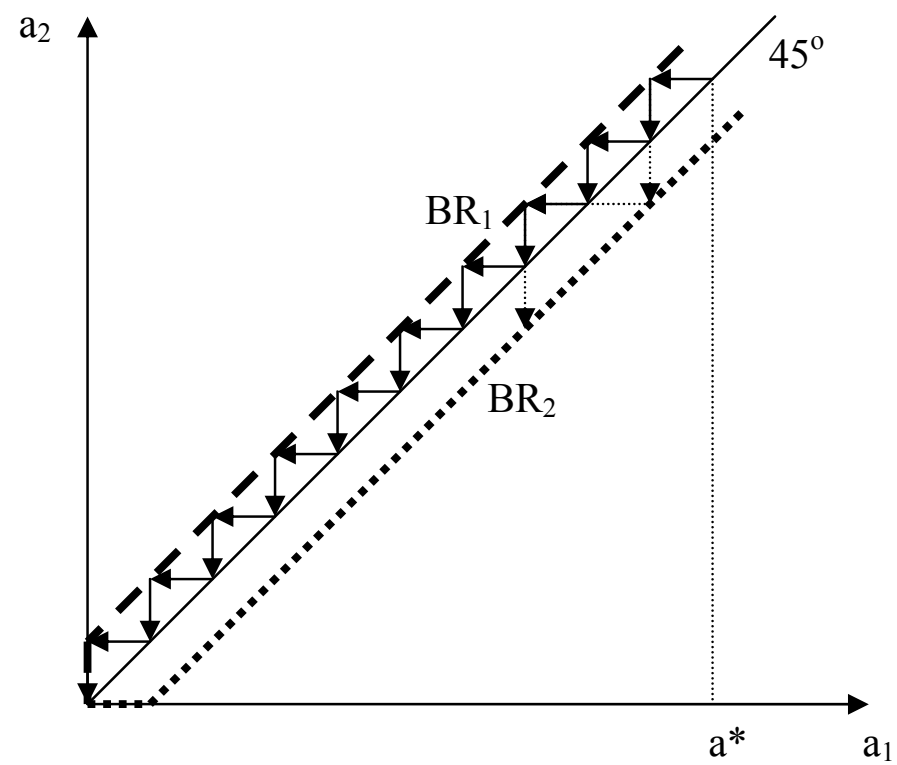

\section{Conclusions}

This analysis shows that cooperation among the members of competing groups is not something we ought to expect. Fundamental contest mechanisms rather suggest that incentives will crowd out cooperation as formal group organization schemes. Our evolutionary narrative indicates, however, that this crowding-out process is liable to take a long time.

Couching the story in a standard game theoretic framework would of course have been an alternative to the evolutionary narrative. Modelling the story as a two-stage game in which the

\footnotetext{
${ }^{11}$ Comparing the shape of the best response function with the one derived by Lee (1995) shows how not observing non-negativity constraints may give rise to rather misleading results. Notice, however, that the reaction functions suggested by Lee (1995) also intersect at the origin and thus identify the correct Nash equilibrium.
} 
group formateurs first select one of the feasible organization schemes $(\mathrm{N}, \mathrm{C}, \mathrm{I}, \mathrm{M}(\mathrm{a}))$ and the group members then choose their individual efforts $\mathrm{x}$ would have yielded the same outcome, namely the subgame perfect Nash equilibrium $\left(I, I ; x_{i k}=\frac{1}{4 n^{2}}\right.$ with $\mathrm{i}=1, \ldots, \mathrm{n}$ and $\left.\mathrm{k}=1,2\right)$. This standard representation does, however, not convey any idea about how the process of incentivizing organizations runs its course. Using the evolutionary narrative or inspecting the extensive form of the game in a $2 \times 2$ set-up (see the numerical example in the appendix) in which the group formateurs can either stick with the status quo or implement the most profitable next step of organizational innovation reveals that all regime switches represent prisoners' dilemmas. The sequence of regime switches from $(\mathrm{N}, \mathrm{N})$ to $(\mathrm{C}, \mathrm{C})$, to the mixed incentive regimes $M$, i.e., $\left(a_{1}=a^{*}, a_{2}=a^{*}\right),\left(a^{*}-1 /(n-1), a^{*}-1 /(n-1)\right),\left(a^{*}-2 /(n-1), a^{*}-2 /(n-1)\right)$, and so on. down to $(I, I) \equiv\left(a_{1}=0, a_{2}=0\right)$ add up to a nested structure of prisoners' dilemmas that resembles the centipede game in which the subgame perfect Nash equilibrium also represents the worst outcome. In the one-shot centipede game subjects in experiments never actually play the Nash equilibrium, and in our dynamic group contest game probably nobody would conjecture that both groups, starting out from the non-cooperative regime $(\mathrm{N}, \mathrm{N})$, immediately switch to the fully incentivized regime (I,I) that yields much lower payoffs for both organizations. Slowly climbing up the game tree from $(\mathrm{N}, \mathrm{N})$ to $(\mathrm{I}, \mathrm{I})$ is, however, a credible development scenario. Moreover, a gradual increase of individual incentives is consonant with the empirical evidence.

The evolutionary process that ratchets up the use of incentives until cooperation completely disappears entails an increase in contest effort. If contest effort is socially wasteful (as we have assumed here in accordance with the rent-seeking literature), the transition to incentivised group organization schemes decreases welfare. If, on the other hand hand, the additional effort is not completely dissipated but rather generates positive external effects, as is, for example, the case when competition-induced producer effort spills over to the consumers, the welfare loss of the producers may be outweighed by the welfare gain of the consumers. Be that as it may, the direct effect of providing individual incentives reduces the well-being of the group members; and this calls for an explanation as to why incentive schemes have become the standard instrument of managing modern organizations. Our analysis provides an answer to this puzzle.

The crowding out of organization schemes that bank on cooperation may also be deplored from a purely ethical point of view. It appears, however, that the benefits from being part of a competitive organization and the warm glow that individuals may derive from being in the 
company of supposedly cooperating peers are to some extent mutually exclusive. This incompatibility need not be perfect since it is well known that cooperation among group members also occurs in groups using incentive schemes. Gächter et al. (2009), for example, show that there is substantial voluntary cooperation in organizations adopting incompletely incentive-compatible contracts. Moreover, their experimental study indicates that experiencing incentive contracts reduces voluntary cooperation in the short run. Notice, however, that this kind of crowding out of cooperation concerns the behavior of the individual group members and not the choice behavior of the whole group, represented perhaps by their respective formateurs. In my analysis, which focuses on and endogenizes the group organization scheme, the behavior of the individual group members is assumed to correspond to the Nash equilibrium of the game defined by the adopted organization scheme. In the substantial literature on the crowding out of cooperation on the part of individual players, the organization scheme is exogenously given and the focus is on the individual group members whose behavior can be more or less cooperative. Even though my approach is quite different from this literature which is nicely surveyed in Gächter et al. (2009), the fundamental question as to why we observe more cooperation than traditional economic analysis predicts is common to both lines of investigation. In the context of endogenous organization schemes this means that the existence of many organizations still using contractual arrangements that leave room for and implicitly solicit cooperation on the part of the individual members needs to be explained. My analysis has not aimed at providing an answer to this question. My model rather provides an explanation for the puzzling and almost all-encompassing - albeit slow proliferation of incentive schemes in modern societies.

I have derived the results using the special assumptions that are standard in the rent-seeking literature. Analyzing richer models that build on the insight gained from the literature on crowding out of individual behavior may reveal the circumstances in which pockets of cooperation-inducing organization schemes can survive in a largely incentivized environment.

\section{Acknowledgements}

The author would like to thank Robert Hofmeister, Sanghack Lee, and Shmuel Nitzan for insightful comments. 


\section{References}

Aidt, T. and Hillman, A. (2008): Enduring rents, European Journal of Political Economy 24, 545-553.

Angelopoulos, K., Philippopoulos, A. and Vassilatos, V. (2009): The social cost of rent seeking in Europe, European Journal of Political Economy 25, 280-299.

Ansink, E. and Weikard, H.P. (2009): Contested water rights, European Journal of Political Economy 25, 247-260.

Arce, D.G. (2010): Corporate virtue: Treatment of whistle blowers and the punishment of violators, European Journal of Political Economy 26, 363-371.

Baik, K.H. (2008): Contests with group-specific public goods prices, Social Choice and Welfare 30, 103-117.

Baik, K.H. and Lee, S. (2007): Collective rent-seeking when sharing rules are private information, European Journal of Political Economy 23, 768-776.

Baik, K.H. and Lee, D. (forthcoming): Do rent-seeking groups announce their sharing rules? Economic Inquiry (http://onlinelibrary.wiley.com/doi/10.1111/j.1465-7295.2009.00280.x/pdf)

Baik, K.H. and Shogren, J.F. (1995): Competitive-share group formation in rent seeking contests, Public Choice 83, 113-126.

Cheikbossian, G. (2008): Heterogeneous groups and rent-seeking for public goods, European Journal of Political Economy 24, 133-150.

Chen, K. and Tang, F. (2009): Cultural differences between Tibetans and ethnic Han Chinese in ultimatum bargaining experiments, European Journal of Political Economy 25, 78-84.

Congleton, R.D., Hillman, A.L. and Konrad, K. eds. (2008): 40 years of research on rent seeking 1\&2, Heidelberg, Springer.

Davis, D. and Reilly, R. (1999): Rent-seeking with non-identical sharing rules: An equilibrium rescued, Public Choice 100, 31-38.

Epstein, G.S. and Mealem, Y. (2009): Group specific public goods, orchestration of interest groups with free riding, Public Choice 139, 357-369.

Gächter, S., Kessler, E. and Königstein, M. (2009): Performance incentives and the dynamics of voluntary cooperation, http://www.vwa.unisg.ch/org/vwa/web.nsf/1176ad62df2ddb13c12568f000482b94/2ddd2b2a9 59a4296c125744a0034d626/\$FILE/GaechterKesslerKoenigstein_12-02-09.pdf

Hausken, K. (2000): Cooperation and between-group competition, Journal of Economic Behavior and Organization 42, 417-425.

Heller, W.B. and Sieberg, K.K. (2010): Honour among thieves: Cooperation as a strategic response to functional unpleasantness, European Journal of Political Economy 26, 351-362.

Hillman, A.L. and Samet, L. (1987): Dissipation of contestable rents by small numbers of contenders, Public Choice 54, 63-82. Reprinted in Congleton et al. (2008).

Hillman, A.L. and Riley, J.G. (1987): Politically contestable rents and transfers, Economics and Politics 1, 17-39. Reprinted in Congleton et al. (2008).

Hillman, A.L. (2009): Hobbes and the prophet Samuel on leviathan government, Public 
Choice 141, 1-4.

Kahana , N. and Liu, Q. (2010): Endemic corruption, European Journal of Political Economy $26,82-88$.

Katz, E. and Tokatlidu, J. (1996): Group competition for rents, European Journal of Political Economy 12, 599-607. Reprinted in Congleton et al. (2008).

Konrad, K.A. (2004): Bidding in hierarchies, European Economic Review 48, 1301-1308. Reprinted in Congleton et al. (2008).

Konrad, K.A. (2009): Strategy and dynamics in contests, Oxford, Oxford University Press.

Lazear, E. and Rosen, S. (1981): Rank-order tournaments as optimum labor contracts, Journal of Political Economy 89, 841-864.

Lee, S. (1995): Endogenous sharing rules in collective-group rent seeking, Public Choice 85, 31-44.

Nitzan, S. (1991): Rent-seeking with non-identical sharing rules, Public Choice 71, 43-50.

Nitzan, S. and Ueda, K. (2010): Prize sharing in collective contests, (http://www.biu.ac.il/soc/ec/wp/2010-08.pdf)

Olson, M. (1965): The logic of collective action, Cambridge MA, Harvard University Press.

Reuben, E. and Tyran, J.R. (2010): Everyone is a winner: Promoting cooperation through allcan-win intergroup competition, European Journal of Political Economy 26, 25-35.

Riechmann, T. and Weimann, J. (2008): Competition as a coordination device: Experimental evidence from a minimum effort coordination game, European Journal of Political Economy $24,437-454$.

Ryvkin, D. (2010): Contests with private costs: Beyond two players, European Journal of Political Economy 26, 558-567.

Tullock, G. (1980): Efficient rent-seeking, in J. Buchanan, Tollison, R. and Tullock, G. (eds.): Toward a theory of rent-seeking society, College Station, Taxas A\&M University Press, 97112. Reprinted in Congleton et al. (2008).

Ueda, K. (2010): Oligopolization in collective rent-seeking, Social Choice and Welfare 19, 613-626.

Ursprung, H.W. (1990): Public goods, rent dissipation, and competition, Economics and Politics 2, 115-132. Reprinted in Congleton et al. (2008). 


\section{Appendix: Numerical example}

The following numerical example is based on the parameter values $n=100, q=98 / 100$, $\mathrm{V}=1000$.

\begin{tabular}{|c|c|c|c|c|}
\hline \multicolumn{2}{|c|}{ organization scheme } & \multirow[t]{2}{*}{$\mathbf{E U}_{\mathrm{i1}}$} & \multirow[t]{2}{*}{$\mathbf{E} \mathbf{U}_{\mathrm{j} 2}$} & \multirow[t]{2}{*}{ comment } \\
\hline group 1 & group 2 & & & \\
\hline no cooperation & no cooperation & 4.975 & 4.975 & "Hobbesian jungle" \\
\hline cooperation & no cooperation & 9.799 & 0.100 & $\begin{array}{c}\text { discovery of co- } \\
\text { operation by group } 1 \\
\end{array}$ \\
\hline cooperation & cooperation & 2.5 & 2.5 & $\begin{array}{l}\text { imitation by group 2: } \\
\text { "cooperative regime" }\end{array}$ \\
\hline$a_{1}=a^{*}=0.499$ & cooperation & 2.551 & 2.399 & $\begin{array}{c}\text { successful first } \\
\text { incentivization by } \\
\text { group } 1\end{array}$ \\
\hline$a_{1}=a^{*}$ & $a_{2}=a^{*}$ & 2.4995 & 2.4995 & imitation by group 2 \\
\hline$a_{1}=a^{*}-1 / 99$ & $a_{2}=a^{*}$ & 4.949 & 0 & \multirow{8}{*}{$\begin{array}{l}\text { mixed incentive } \\
\text { schemes } \\
\text { with increasing } \\
\text { incentivization }\end{array}$} \\
\hline$a_{1}=a^{*}-1 / 99$ & $a_{2}=a^{*}-1 / 99$ & 2.449 & 2.449 & \\
\hline$a_{1}=a^{*}-2 / 99$ & $a_{2}=a^{*}-1 / 99$ & 4.849 & 0 & \\
\hline \multicolumn{4}{|c|}{$\begin{array}{l}\bullet \\
\bullet \\
\bullet \\
\bullet\end{array}$} & \\
\hline$a_{1}=a^{*}-48 / 99$ & $a_{2}=a^{*}-48 / 99$ & 0.099 & 0.099 & \\
\hline$a_{1}=a^{*}-49 / 99$ & $a_{2}=a^{*}-48 / 99$ & 0.149 & 0 & \\
\hline$a_{1}=a^{*}-49 / 99$ & $a_{2}=a^{*}-49 / 99$ & 0.049 & 0.049 & \\
\hline$a_{1}=0$ & $a_{2}=a^{*}-49 / 99$ & 0.055 & 0 & \\
\hline$a_{1}=0$ & $a_{2}=0$ & 0.025 & 0.025 & $\begin{array}{l}\text { "fully incentivized } \\
\text { regime" }\end{array}$ \\
\hline
\end{tabular}


Table 1: Interaction of groups adopting pure organization schemes

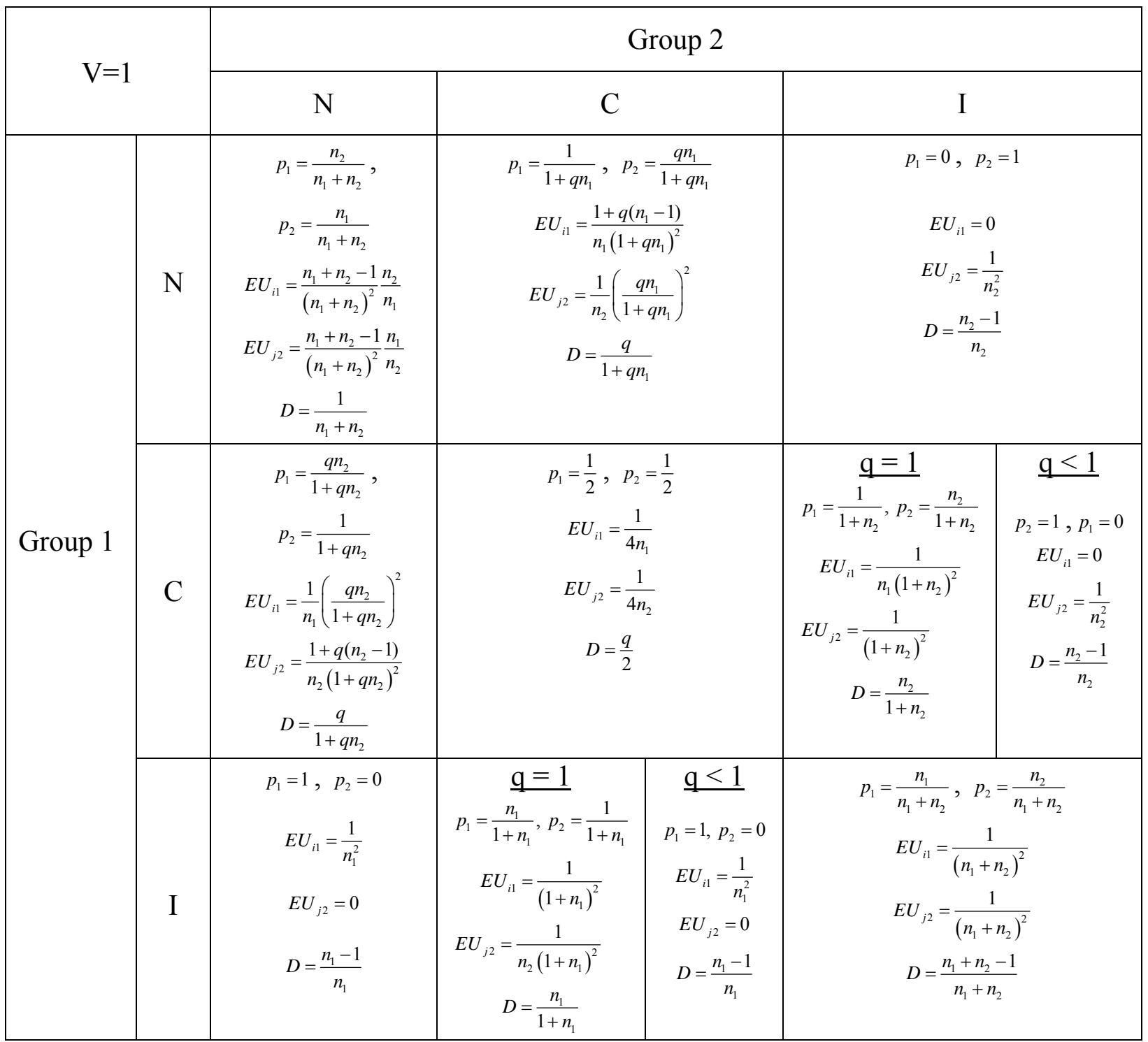

